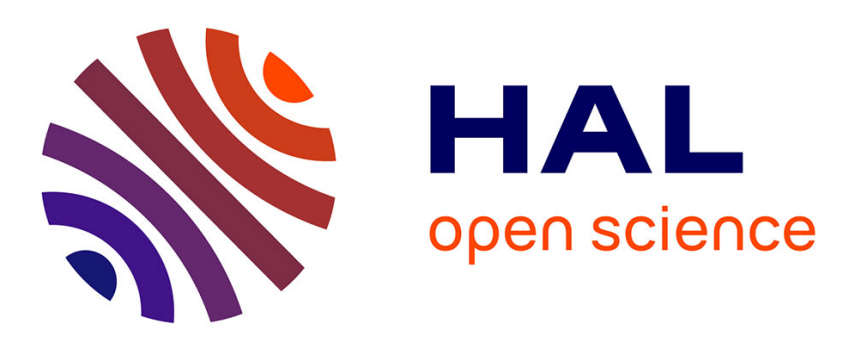

\title{
Immunoselection and characterization of a human genomic PPAR binding fragment located within POTE genes
}

Hossam Murad, Philippe Collet, Emilie Brunner, Hervé Schohn, Philippe

Becuwe, Marie-Dominique Devignes, Michel Dauça, Lionel Domenjoud

\section{To cite this version:}

Hossam Murad, Philippe Collet, Emilie Brunner, Hervé Schohn, Philippe Becuwe, et al.. Immunoselection and characterization of a human genomic PPAR binding fragment located within POTE genes. Biochimie, 2006, 10.1016/j.biochi.2006.09.017 . inria-00103844

\section{HAL Id: inria-00103844 \\ https://hal.inria.fr/inria-00103844}

Submitted on 5 Oct 2006

HAL is a multi-disciplinary open access archive for the deposit and dissemination of scientific research documents, whether they are published or not. The documents may come from teaching and research institutions in France or abroad, or from public or private research centers.
L'archive ouverte pluridisciplinaire HAL, est destinée au dépôt et à la diffusion de documents scientifiques de niveau recherche, publiés ou non, émanant des établissements d'enseignement et de recherche français ou étrangers, des laboratoires publics ou privés. 


\section{Immunoselection and characterization of a human genomic}

PPAR binding fragment located within POTE genes

Hossam Murad ${ }^{\mathrm{a}, *}$, Philippe Collet ${ }^{\mathrm{a}, *}$, Emilie Brunner ${ }^{\mathrm{a}}$, Hervé Schohn $^{\mathrm{a}}$,

Philippe Bécuwe ${ }^{\mathrm{a}}$, Marie-Dominique Devignes ${ }^{\mathrm{b}}$, Michel Dauça ${ }^{\mathrm{a}}$,

Lionel Domenjoud ${ }^{\mathrm{a}, \dagger}$

aEA3446 "Proliférateurs de Peroxysomes" Université Henri Poincaré-Nancy I, Faculté des

Sciences, BP239, 54506 Vandoeuvre-les-Nancy, France

${ }^{\mathrm{b}}$ CNRS-UMR 7503, Laboratoire Lorrain de Recherche en Informatique et ses Applications, 54506 Vandoeuvre-les-Nancy, France

${ }^{*}$ H.M and P.C.participated equally in this study.

${ }^{\dagger}$ To whom correspondence should be addressed.

Tel: (33) 3.83.68.42.15. Fax: (33) 3.83.68.42.19.

E-mail address: Lionel.Domenjoud@sscbiol.uhp-nancy.fr

\section{Abstract}

Peroxisome proliferator-activated receptors (PPARs) are ligand-inducible transcription factors and belong to the nuclear hormone receptor superfamily. They form heterodimers with retinoid X receptor $(\mathrm{RXR})$ and bind to specific PPAR-response elements. To identify novel PPAR target genes, we developed an affinity method to isolate human genomic fragments containing binding sites for PPARs. For this, an antibody raised against all PPAR subtypes was used. Immunoselected fragments were amplified and sequenced. One of them, ISF1029, was mapped 
by BLAT and BLAST searches on different human chromosomes, downstream of several POTE genes. ISF1029 contained three hexamers strongly related to the AGGTCA motif organized according to a DR0/3 motif. The latter was found to bind to PPAR $\alpha$ in gel mobility shift and supershift assays and to exhibit a downregulation potentiality in transfection experiments under clofibrate treatment. POTE genes were shown to be highly expressed in human Caco-2 colorectal adenocarcinoma cells and downregulated by fenofibrate and 9-cis-retinoic acid, as attested by RT-PCR assays. Microarray analysis confirmed and extended to the human T98-G glioblastoma cells, the downregulation of several POTE genes expression by Wy-14,643, a potent PPAR $\alpha$ activator. Our data provide new insights about the pleiotropic action of PPARs.

Keywords: Peroxisome proliferator-activated receptors; PPARs; PPAR target genes; POTE genes.

Abbreviations: CPT1 $\alpha$, carnitine palmitoyltransferase $1 \alpha$; DR, Direct repeat; FCS, fetal calf serum; GAPDH, glyceraldehyde 3 phosphate dehydrogenase; ISF, immunoselected fragment; PPAR, peroxisome proliferator-activated receptor; PPRE, peroxisome proliferator responsive element; RE, response element; RXR, retinoïd X receptor.

\section{Introduction}

The peroxisome proliferator-activated receptors (PPARs) are ligand-activated transcription factors belonging to the nuclear hormone receptor superfamily [1]. Three PPAR isotypes have been characterized: PPAR $\alpha$, PPAR $\beta / \delta$ and PPAR $\gamma$. Depending on the tissues in which they are 
expressed, these isotypes are invoved in different cellular functions including fatty acid cellular metabolism as well as the regulation of the balance between cell proliferation, survival and differentiation [2]. PPAR transcriptional activity depends on the binding of synthetic or endogenous ligands and requires heterodimerization with the retinoid $\mathrm{X}$ receptor for binding to DNA at specific sites, defined as direct repeats of hormone response elements, separated by one base (DR-1).

To discover novel target genes for these receptors, we used an immunoselection approach. A DNA library of high-affinity binding sites for PPARs was prepared from human genomic DNA. DNA fragments bound to PPAR were immunoprecipitated using an anti-PPAR antiserum produced in our laboratory and characterized as recognizing all PPAR subtypes [3] in order to obtain an overall collection of putative PPREs. The immunoselected fragments (ISFs) were cloned and sequenced. By BLAST analysis, one of the PPARs binding sites was found located on different human chromosomes downstream of the coding sequences of several POTE genes. The primate-specific POTE gene family, which is selectively expressed in placenta, prostate, ovary, and testicular, as well as in prostate cancer, consists of at least 13 closely related paralogs located on human chromosomes $2,8,13,14,15,18,21$ and 22 [4-6]. The POTE genes encode a highly homologous group of proteins that all contain an $\mathrm{NH}_{2}$-terminal cysteine-rich domain followed by a series of ankyrin repeats and spectrin-like helices. Because the POTE proteins are mainly expressed in testis and many cancers but only in a few normal tissues, it has been suggested that they are new members of the cancer-testis antigen family [7]. Until now, no information has been provided concerning the regulation of POTE genes. On the other hand, ligand activation of PPAR $\gamma$ induces growth inhibition in prostate cell lines and a prolonged stabilization of prostatespecific antigen in patients [8]. 
In the current study, we reveal that a conserved sequence located downstream of several POTE genes binds PPAR in shift and supershift assays, and downregulates the expression of a reporter gene in cotransfection experiments under the action of a PPAR $\alpha$ agonist. The downregulation was confirmed by RT-PCR and microarray analyses with different human cell lines.

\section{Materials and methods}

\subsection{Plasmids}

Plasmids used for in vitro protein synthesis for PPARs and RXRs were kind gifts from Pr W. Wahli (University of Lausanne, Switzerland) and Dr A. Pujol (IGBMC, Illkirch, France), respectively. Reporter pGL3 plasmids used for transfection experiments were constructed by cloning the potential PPAR binding site (RE1029) of ISF1029 upstream from the luciferase reporter gene.

2.2. Immunoprecipitation of PPAR binding human genomic DNA fragments

The immunoselection protocol used (Fig.1) was derived from the method established by Rudert and Gronemeyer [9] with adaptations [10]. Since PPAR target genes were first shown to be expressed in the liver, we decided to use genomic DNA and nuclear proteins from the human hepatoblastoma HepG2 cell line [11] for immunoprecipitation of PPRE sequences. Prepared total DNA was incubated with $15 \mu \mathrm{g}$ of HepG2 cell nuclear proteins (providing PPARs and RXRs) extracted as described [12]. Previously characterized polyclonal antibodies that are raised against 
all PPAR isotypes [3] were added at a 1:2500 final dilution and incubation was carried out for $1 \mathrm{~h}$ at $37^{\circ} \mathrm{C}$. Then, protein A-Sepharose CL- $4 \mathrm{~b}$ beads were added $(10 \mu \mathrm{l}$ of a $50 \% \mathrm{w} / \mathrm{v}$ slurry in $10 \mathrm{mM}$ Tris- $\mathrm{HCl} \mathrm{pH} 7.5,1 \mathrm{mM}$ EDTA, $0.1 \%$ Triton X-100) and the incubation was continued for $1 \mathrm{~h}$ at $37^{\circ} \mathrm{C}$ with constant and gentle agitation. The protein A-Sepharose beads with the adsorbed DNA were pelleted by centrifugation $\left(10,000 \mathrm{~g}, 10 \mathrm{~min}, 4^{\circ} \mathrm{C}\right)$. The supernatant was discarded and the beads were washed twice in $150 \mathrm{mM} \mathrm{KCl}, 10 \mathrm{mM}$ Tris- $\mathrm{HCl} \mathrm{pH} 7.5,1 \mathrm{mM}$ EDTA and $0.1 \%$ Triton X-100. The recovered DNA was eluted by incubating the beads for $15 \mathrm{~min}$ at $45^{\circ} \mathrm{C}$ in $200 \mathrm{mM}$ sodium acetate, $50 \mathrm{mM}$ Tris- $\mathrm{HCl} \mathrm{pH} 8.0,0.5 \%$ SDS and $5 \mathrm{mM}$ EDTA. Then, it was extracted with phenol/chloroform, precipitated with ethanol in the presence of $40 \mu \mathrm{g}$ glycogen as a carrier and resuspended in $20 \mu \mathrm{l} \mathrm{H}_{2} \mathrm{O}$. The immunoselected DNA fragments were amplified and cloned as described [10]. Sequencing was achieved by Genomexpress. To map ISF1029 in the human genome, BLAST searches were performed at the National Center for Biotechnology Information (NCBI) (http://www.ncbi.nlm.nih.gov/BLAST). BLAT searches were carried out using the UCSC Genome Browser Database web server at the University of California, Santa Cruz (http://genome.ucsc.edu) [13].

\subsection{Southwestern blotting}

The ISF clones were spotted in an ordered array onto a nylon membrane and grown for $4 \mathrm{~h}$. The DNAs of the clones were released through alkaline lysis and tested for their affinity to PPARs. Binding was carried out at $4^{\circ} \mathrm{C}$ for 30 min with $12.5 \mu \mathrm{g}$ of HepG2 nuclear proteins (containing RXRs) and $10 \mu 1$ of both $\left[{ }^{35} \mathrm{~S}\right]$ methionine-labeled PPAR isotype. The latter were synthesized from pSG5 expression vectors using $\left[{ }^{35}\right.$ S]methionine (Amersham) and the TNT7 rabbit reticulocytes in vitro transcription and translation system (Promega). Thereafter, the filters were 
washed twice for 10 min with the binding buffer under gentle agitation at $37^{\circ} \mathrm{C}$, then dried and exposed overnight at room temperature to X-ray films.

2.4. Gel mobility shift and supershift assays

Gel retardation assays were performed with RE1029 (Fig.1) corresponding to the putative PPAR binding site found in the sequence of ISF1029. After preincubation for $15 \mathrm{~min}$ with the reaction mixture, the labeled RE1029 probe (1pmol) was added to $12.5 \mu \mathrm{g}$ of HepG2 nuclear proteins in the binding buffer containing 10\% glycerol, $10 \mathrm{mM}$ HEPES $\mathrm{pH}$ 7.9, $10 \mathrm{mM} \mathrm{KCl}, 0.5 \mathrm{mM}$ DTT, $1.25 \mathrm{mM} \mathrm{MgCl} 2$ and $1 \mu \mathrm{g}$ poly dI-dC. The reaction was carried out at $37^{\circ} \mathrm{C}$ for $15 \mathrm{~min}$. In supershift assays, the anti-panPPAR [3] (diluted 1/40) or the anti-PPAR $\alpha$ [14] antibodies (diluted 1:40 or 1:1000) were added and another incubation was carried out for $15 \mathrm{~min}$. The resulting complexes were resolved on $4 \%$ native polyacrylamide gels in 1x Tris-borate/EDTA buffer.

2.5. Transfection assays

COS-7 cells were seeded in 6-well dishes at $10^{6}$ cells per well and grown in DMEM supplemented with $10 \%$ fetal calf serum (FCS). After an initial 8-hours adhesion step, each well received equal quantities of polyethylenimine/DNA complexes containing $1 \mu \mathrm{g}$ of the pGL3SV40 promoter-luc reporter plasmid (harboring RE1029) together with $0.5 \mu \mathrm{g}$ DNA of pSG5 $\beta$ galactosidase vector alone to check the transfection efficiency. Cotransfection was performed with $0.5 \mu \mathrm{g}$ of pSG5-mPPAR $\alpha$ and $\mathrm{pSG} 5-\mathrm{mRXR} \alpha$ expression vectors for assays. Cells were transfected for $12 \mathrm{~h}$, and the medium was replaced with fresh medium containing either vehicle 
alone $(0.1 \% \mathrm{DMSO})$ or $500 \mu \mathrm{M}$ clofibrate in $0.1 \%$ DMSO. After a $24-\mathrm{h}$ treatment, cells were harvested in $150 \mu 1$ of $0.25 \mathrm{M}$ Tris- $\mathrm{HCl}, \mathrm{pH} 8.0$, and lysed by three freeze-thaw cycles. After centrifugation at $10,000 \mathrm{~g}$ for $10 \mathrm{~min}$ at $4^{\circ} \mathrm{C}$, the supernatant was used for $\beta$-galactosidase and luciferase activity assays as previously described [10]. The experimental values from at least three independent transfection assays were normalized using $\beta$-galactosidase values as an internal standard.

2.6. Semiquantitative RT/PCR analysis

As a first step, expression of POTE genes was assessed in seven different human cell lines in order to select the cell line expressing POTE genes at the highest level. T98-G [15] glioblastoma cells, SH-SY5Y [16] neuroblastoma cells, HepG2 hepatoblastoma cells [11], Caco-2 [17] and HCT 116 [18] colorectal carcinoma cells, MCF-7 breast adenocarcinoma cells [19] and PC3 prostate carcinoma cells [20] were grown as previously reported for each cell line. The selected cell line was treated for $24 \mathrm{~h}$ either with vehicle (0.1\% DMSO) alone or with $500 \mu \mathrm{M}$ fenofibrate simultaneously or not with $1 \mu \mathrm{M}$ 9-cis retinoic acid.

Total RNA was prepared using the guanidium isothiocyanate-phenol-chloroform method [21] and submitted to electrophoresis on $1 \%$ agarose gels containing ethidium bromide to verify the absence of genomic DNA contamination. Semiquantitative RT/PCR analysis was carried out as previously reported [22]. PCR primers for POTEs were selected in a common open reading frame of the different human genes [7] (Table 1). Primers for glyceraldehyde 3 phosphate dehydrogenase $(\mathrm{GAPDH})$ and carnitine palmitoyltransferase $1 \alpha(\mathrm{CPT} 1 \alpha)$ genes were chosen from published nucleotide sequences $[23,24]$ (Table 1). GAPDH and CPT1 $\alpha$ were used as 
internal standard and positive control [25], respectively. Each primer was added at a final concentration of $0.2 \mu \mathrm{M}$ in a $50 \mu \mathrm{l}$ reaction mixture, containing $200 \mathrm{ng}$ cDNA, $0.2 \mathrm{mM}$ of each dNTP, $1.5 \mathrm{mM} \mathrm{MgCl} 2,1 \times$ PCR reaction buffer, and $2.5 \mathrm{U}$ Taq polymerase. An initial denaturation step was carried out for $3 \mathrm{~min}$ at $94^{\circ} \mathrm{C}$. The following PCR program was performed in an automated thermal cycler (BioRad): denaturation at $94^{\circ} \mathrm{C}$ for $40 \mathrm{~s}$, annealing for $40 \mathrm{~s}$ at $54^{\circ} \mathrm{C}$, then elongation at $72^{\circ} \mathrm{C}$ for $40 \mathrm{~s}$. This program was completed with a final extension for 10 min at $72{ }^{\circ} \mathrm{C}$. Amplified DNA fragments were separated on a $2 \%$ agarose gel and visualized by UV transillumination after ethidium bromide staining. Fluorescence intensity was quantified using a Gel Doc 2000 system (Bio-Rad). The PCR products amounts for POTE and GAPDH were all within the linear phase of the reaction using 25 PCR cycles for POTE, 18 cycles for GAPDH and 28 cycles for CPT1 $\alpha$ under these experimental conditions.

\subsection{Microarray analysis}

A $25 \mathrm{~K}$ human oligonucleotide microarray covering most of the human known transcripts has been used for this transcriptome analysis. This oligonucleotide collection is a public resource (Réseau National des Génopoles, France and MRC, UK). Information about these oligonucleotides ( $\sim 51$ bases oligonucleotides), designed by the Institut de Pharmacologie Moléculaire et Cellulaire (Valbonne Sophia-Antipolis, France), is available at http://medcal.ipmc.cnrs.fr:8080/mediante. The oligonucleotides (synthesized by Proligo) were diluted to $50 \mu \mathrm{M}$ in $50 \%$ DMSO, $100 \mathrm{mM}$ phosphate buffer and spotted using a $\mu$ GridII arrayer (BioRobotics) onto slides coated with an Hydrogel layer ( $\mathrm{H}$ slides, Schott). Total RNA (200 ng/sample) from T98-G cells, treated or not with Wy-14,643 for $24 \mathrm{~h}$, were 
amplified by linear PCR and the amplification products were labeled with dUTP-Cy3 or dUTPCy5 by random priming (Bioprime, InVitrogen) and purified using Nucleospin Extract II columns (Macherey Nagel). Labeled cDNAs were hybridized in a Discovery station using ChipHybe 80 hybridization buffer at $42^{\circ} \mathrm{C}$ for $12 \mathrm{~h}$ without any final stringent washes (Ventana Medical System hybridization automate, reagents and microarray hybridization procedure). All the protocols used are available at http://www-microarrays.u-strasbg.fr/Chips/index.html. After slides scanning (ScanArray4000, Perkin-Elmer), the obtained TIFs images were quantified using Imagene 6 (BioDiscovery) and the raw data were normalized using the Quantile method (homemade program). For each different RNA sample a flip-flop experiment was performed using a reference RNA. The normalized ratio RNA sample/reference RNA $\left(\log _{2}\right)$ was calculated and this ratio was directly used for the comparison of different samples.

\subsection{Statistical analysis}

The statistical significances of differences between data from transfection and RT/PCR assays were assessed by Student's t-test $(P<0.05)$. The data represent the mean $\pm \mathrm{SD}$ of at least three independent experiments.

\section{Results}

A PPAR binding site in a DNA fragment is likely to be biologically relevant if it satisfies the following criteria: (i) binding of PPAR should be of high affinity as determined by filter binding, gel mobility shift and supershift assays; (ii) the PPAR binding site should confer PPAR liganddependent expression or suppression of expression. 
The different steps of the immunoselection/PCR protocol used to isolate, amplify, and clone human genomic DNA fragments able to bind to PPARs are shown in Figure 1. Binding capacities of the different ISF clones were tested by Southwestern blotting using in vitro translated, radiolabeled PPARs. Proteins were hybridized to the baked nylon bearing the spotted ISFs. The positive (canonical PPRE sequence) and negative (empty plasmid) controls ensured specificity of the signals obtained (Fig.1). Forty positive clones were obtained, 11 clones were sequenced and one of them (ISF5148) was published [10].

If the PPAR-binding fragments are specifically immunoprecipitated with the anti-PPAR antiserum, indicating that DNA-PPAR-protein complexes have been formed, they should then exhibit a high homology with TG(A/T)CCT motifs from already known DR1 sequences. Sequence conservation of the TG(A/T)CCT motif in the ISF library was evaluated by insert sequencing. Several DR1 motifs were found (data not shown), confirming that our immunoselection experiment was able to retrieve canonical PPREs from the human genome.

\subsection{ISF1029 is located within different POTE genes}

Our further investigations were focused on ISF1029 for the following reasons. A BLAT homology-based search performed on the last version of the human genome assembly revealed that the ISF1029 sequence (Fig.1) was found completely identical to sequences located downstream of POTE-22 and POTE-14, genes which were recently discovered. In addition, numerous less similar sequences were also found downstream of POTE-14, POTE-2, POTE-22, POTE-15, POTE-18 and POTE-21 genes coding regions suggesting an association of these 
sequences with the POTE genes during their evolution. Finally, as the function of the POTE genes is unknown, the connection of PPARs to POTEs could open up the possibility of determining the function of the POTE genes and at the same time of understanding an additional mechanism of PPARs action.

The 3'-end of ISF1029 (called RE1029 throughout the text) contains three hexamers strongly related to the AGGTCA motif and spaced by 0 and 3 nucleotides, respectively, creating a DRO/3 sequence (Fig. 1). A BLAT search identified numerous sequences containing the 21 nucleotides of the DR0/3 motif, dispersed on chromosomes 2, 14, 15, 18, 21 and 22 within POTE genes (Table 2). Most interestingly, the RE1029 sequence is located downstream of all POTE genes except POTE- 8 , POTE-2 $\beta,-2 \beta^{\prime}$ and $-2 \delta$ which do not exhibit this sequence in their neighbouring. It is also systematically located upstream of the prostate-specific P775P gene [26].

\subsection{PPAR binds to RE1029}

Gel mobility shift and supershift DNA binding experiments were performed. A retarded band was observed when the radiolabeled RE1029 probe representing the DR0/3 putative PPAR binding site was incubated with HepG2 cell nuclear proteins (Fig. 2, lane 1). Moreover, the retarded complex was supershifted with polyclonal antibodies (diluted 1:40) directed against either all PPAR isotypes (Fig. 2, lane 2) or against PPAR $\alpha$ (Fig. 2, lane 3). It is likely that the antibody was in excess because when the anti-PPAR $\alpha$ antibody was used at a 1:1000 final dilution the return of the shift band was observed (data not shown). No reproducible results were obtained with anti-PPAR $\beta$ or anti-PPAR $\gamma$ antibodies (data not shown) leading us to focus our investigations on the action of PPAR $\alpha$. 
We investigated whether RE1029 could confer PPAR-dependent regulation to a reporter gene. Cotransfection experiments were carried out with RE1029 sequence cloned upstream of the SV40 promoter coupled to the luciferase reporter gene, with pSG5-mPPAR $\alpha$ and pSG5$\mathrm{mRXR} \alpha$ expression vectors. Transfected cells were treated or not with $500 \mu \mathrm{M}$ clofibrate, a potent PPAR $\alpha$ agonist, for $24 \mathrm{~h}$. When cells were cotransfected with the RE1029-SV40 promoter-luc construction and with expression vectors, then treated with clofibrate, a 5.4-fold decrease in the relative luciferase/ $\beta$-galactosidase activity was observed as compared to untreated cells (10.8 versus 1.99$)$.

3.5. PPAR $\alpha$ and RXR $\alpha$ agonists downregulate POTE expression in Caco-2 cells

Seven well-characterized human cell lines were examined for POTE expression. Three independent cell cultures were carried out for total RNA extraction and semiquantitative RT/PCR analysis with specific primers. The relative POTE mRNA level was measured and compared to that of GAPDH used as an internal control. The human cell lines exhibited very different levels of POTE mRNA (Fig. 3). The highest level was expressed by Caco-2 colorectal adenocarcinoma cells. POTE genes displayed average expression in MCF-7 breast adenocarcinoma cells and HepG2 hepatoblastoma cells. The lowest levels of POTE mRNA were found in HCT 116 colorectal carcinoma cells, T98G glioblastoma cells and SH-SY5Y neuroblastoma cells. No expression of POTE genes was detected in the PC3 human prostate cells confirming previous 
data [6]. On the basis of these data, the Caco-2 cell line was selected for the following studies as it expresses POTEs at a high level.

Fenofibrate, a potent PPAR $\alpha$ agonist, was chosen instead of clofibrate in order to verify that the downregulation obtained in transfection experiments was not due to the nature of the PPAR activator. To verify that Caco- 2 cells were sensitive to the PPAR $\alpha$ activator, the CPT1 $\alpha$ mRNA level was determined after fenofibrate treatment. As expected, it was found increased in fenofibrate-treated Caco-2 cells indicating that the treatment was efficient (data not shown).

As PPARs heterodimerize with RXRs before binding to response elements of target genes, we investigated by semiquantitative RT/PCR the alone and combined effects of their agonists on the POTE mRNA level of Caco-2 cells treated for $24 \mathrm{~h}$ with $500 \mu \mathrm{M}$ fenofibrate and/or $1 \mu \mathrm{M}$ 9-cis retinoic acid. As shown in Figure 4, a significant decrease was noted when the cells were treated with fenofibrate or 9-cis-retinoic acid alone. The decrease was more important when Caco-2 cells were simultaneously treated with fenofibrate and 9-cis-retinoic acid (Fig. 4).

3.6. Expression of several POTEs is downregulated by a PPAR $\alpha$ activator

As RT-PCR experiments were carried out with primers selected in a common open reading frame of the POTE paralogs, it was not possible to attribute the downregulation observed to a particular POTE gene. In order to define more precisely the action of the PPAR $\alpha$ agonist, we performed a microarray cDNA analysis. The glioblastoma T98-G cell line was chosen as its origin is different from that of the Caco-2 cell line. T98-G cells were treated for $24 \mathrm{~h}$ with Wy-14,643, another potent PPAR $\alpha$ activator. The $25 \mathrm{~K}$ human oligonucleotide microarray was used since it contains probes for POTE-15, POTE-18, POTE-21 as well as for ANKRD26 and ANKRD30A (two 
POTE-related genes). As shown in Table 3, a general decrease in the contents of the mRNAs encoded by these genes was observed in Wy-14,643-treated T98-G cells.

\section{Discussion}

In this study, we have immunoselected, amplified and sequenced a PPAR-binding human genomic DNA fragment (ISF1029) present in several completely identical copies located in downstream regions of POTE-22 and POTE-14. Less similar sequences were also found downstream of the coding sequences of POTE-2, POTE-15, POTE-18 and POTE-21. This finding led us to focus our investigations on this PPAR-binding DNA fragment and particularly on its putative PPAR-binding RE1029 site.

The RE1029 sequence contains three hexamers strongly related to the AGGTCA motif and disposed according to a DR0 followed by a DR3 sequence. Our data are in good agreement with a previous study concerning the PPAR binding preferences [27]. Using an immunoaffinity method with antibodies directed to the N-terminus myc epitope tag of PPAR $\alpha$, Castelein et al have reported that one half of the recovered sequences contained two hexamers related to the consensus half-site organized as DR1, DR0, PAL0 (palindromic elements without interspacing) or as DR3, in diminishing order of frequency [27]. When the RE1029 sequence was used as a probe and incubated with HepG2 cell nuclear extracts, a retarded complex was obtained. The presence of PPAR $\alpha$ in the retarded complex was attested by supershift experiments with antipanPPAR and anti-PPAR $\alpha$ antibodies.

POTE family genes have emerged from an ANKRD26-like ancestor by duplication and spreading across eight human chromosomes. These genes can be sorted into 3 groups based on sequence 
similarity [6]. POTE-8 belongs to group 1. This gene does not harbour any RE1029 sequence as it is the cases for ANKRD26 and ANKRD30A, two genes which are the most evolutionarily related to POTE-8 (Table 2). Group 2 comprises POTE-15, POTE-18 and POTE-21. Each gene contains two relatively well conserved RE1029 sequences in their downstream regions. Group 3 contains two sets of POTE genes. In the first set, POTE-14 and POTE-22 exhibit in their downstream regions the highest number of sequences completely identical to RE1029, with 7 and 4 sequences for POTE-14 and POTE-22, respectively (Table 2). In addition, RE1029 sequences were only found for POTE- $2 \alpha$ ( 3 sequences) and $-2 \gamma$ ( 1 sequence) which emerged from the same root of the phylogenetic tree [6], meanwhile no RE1029 sequences were found for POTE$2 \beta,-2 \beta^{\prime}$ and $-2 \delta$ (Table 2). It is noteworthy that no transcript is deposited in the data banks for POTE- $2 \beta,-2 \beta^{\prime}$ and $-2 \delta$, whereas there are present for POTE- $2 \alpha$ and $-2 \gamma$ which both contain RE1029 sequences.

We have further characterized the RE1029 potentialities by testing its ability to mediate PPAR and RXR agonists responses in cotransfection experiments. When cells were cotransfected with plasmids containing RE1029, PPAR $\alpha$ and RXR $\alpha$ and then treated with clofibrate (a potent PPAR $\alpha$ activator), a decrease was observed in luciferase activity. These data suggest that the RE1029 binding is able to transregulate the reporter gene expression. Our results extend those of Bardot et al who showed that PPAR $\alpha$ can bind to an oligonucleotide with two TGACCT motifs spaced by more than one nucleotide [28]. It has been emphasized that an intact canonical DR1 element is not required for PPAR binding. In fact, the 5'-flanking region of the CPT II gene that binds PPAR $\alpha$ in vivo in a chromatin immunoprecipitation assay does not contain a DR1 motif but only one half-site which is a perfect consensus sequence (TGACCT) without any clearly recognizable second half-site (CAGCAC). The latter contains only one match to the consensus, 
which seems to be irrelevant for the binding of PPAR $\alpha$ and suggest that the definition of a PPRE for PPAR may need to be expanded [29].

Using the Caco-2 cell line which expresses POTE genes at a high level, we found that fenofibrate and 9-cis-retinoic acid induced a decrease in the POTE mRNA content. This result has been generalized and precised by cDNA microarray experiments with a microarray containing probes for different POTEs. A decrease was observed in the transcript levels of POTE-15, POTE-18 and POTE-21 in T98-G cells treated with Wy-14,643. The role(s) of the POTE proteins is (are) not well defined. The POTE-21 protein localizes in the inner side of the cell membrane and might facilitate or intercept signaling across the plasma membrane and play a role in intercellular communication [30]. We have recently reported that PPAR $\alpha$ regulates the expression of the gene encoding the semaphorin $6 \mathrm{~B}$, a protein which is also involved in intercellular communication [22]. PPAR $\alpha$-dependent downregulation of genes has already been reported in other major pathways including amino metabolism (transamination, deamination, urea cycle, oxidation of alpha keto acids and synthesis of amino acid derived-products), steroid metabolism, acute phase response and inflammation [31]. The precise(s) molecular mechanism(s) behind these downregulations is (are) still unknown and require(s) further investigation.

In summary, we have isolated and characterized a PPAR binding sequence located within POTE genes which is involved in the regulation of their expressions. The biological significance and importance of this control exerted by PPARs deserve further investigation. 
We thank Pr. W. Wahli (University of Lausanne, Switzerland) and Dr A. Pujol (IGBMC, Illkirch, France), for the kind gift of the different cDNAs used in the present study. H. Murad received a fellowship from the Atomic Energy Commission (Syria). This work was supported by grants from Association pour la Recherche contre le Cancer (ARC), Ligue contre le Cancer (Comités de Meurthe et Moselle et de Haute Marne), Plan Etat-Région Lorraine and Henri Poincaré-Nancy I University (BQR).

\section{References}

[1] Committee N.R.N., Nuclear Receptors Nomenclature Committee A unified nomenclature system for the nuclear receptor superfamily, Cell 97 (1999) 161-163.

[2] Feige J.N., Gelman L., Michalik L., Desvergne B., Wahli W., From molecular action to physiological outputs : Peroxisome proliferator-activated receptors are nuclear receptors at the crossroads of key cellular functions, Progr. Lipid Res. 45 (2006) 120-159.

[3] Braissant O., Foufelle F., Scotto C., Dauca M., Wahli W., Differential expression of peroxisome proliferator-activated receptors (PPARs): tissue distruburion of PPAR alphabeta, and gamma in the adult rat, Endocrinology 137 (1996) 354-366.

[4] Bera T.K., Huynh N., Maeda H., Sathyanarayana B.K., Lee B., Pastan I., Five POTE paralogs and their splice variants are expressed in human prostate and encode proteins of different lengths, Gene 337 (2004) 45-53.

[5] Bera T.K., Zimonjic D.B., Popescu N.C., Sathyanarayana B.K., Kumar V., Lee B., Pastan I., POTE, a highly homologous gene family located on numerous chromosomes and 
expressed in prostate, ovary, testis, placenta, and prostate cancer, Proc. Natl. Acad. Sci. U.S.A 99 (2002) 16975-16980.

[6] Hahn Y., Bera T.K., Pastan I.H., Lee B., Duplication and extensive remodeling shaped POTE family genes encoding proteins containing ankyrin repeat and coiled coil domains, Gene 366 (2006) 238-245.

[7] Bera T.K., Saint Fleur A., Lee Y., Kydd A., Hahn Y., Popescu N.C., Zimonjic D.B., Lee B., Pastan I., POTE paralogs are induced and differentially expressed in many cancers, Cancer Res. 66 (2006) 52-56.

[8] Mueller E., Smith M., Sarraf P., Kroll T., Aiyer A., Kaufman D.S., Oh W., Demetri G., Figg W.D., Zhou X.P., Eng C., Spiegelman B.M., Kantoff P.W., Effects of ligand activation of peroxisome proliferator-activated receptor $\gamma$ in human prostate cancer, , Proc. Natl. Acad. Sci. U.S.A 97 (2000) 10990-10995.

[9] Rudert F., Gronemeyer H., Retinoic acid-response elements with a highly repetitive structure isolated by immuno-selection from genomic DNA, J. Steroid Biochem. Mol. Biol. 46 (1993) 121-133.

[10] Collet P., Domenjoud L., Devignes M.D., Murad H., Schohn H., Dauça M., The human semaphorin 6B gene is downregulated by PPARs, Genomics 83 (2004) 1141-1150.

[11] Aden D.P., Fogel A., Plotkin S., Damjanov I., Knowles B.B., Controlled synthesis of HbsAg in a differentiated human liver carcinoma-derived cell line, Nature 282 (1979) 615616.

[12] Dignam J.D., Lebovitz R.M., Roeder R.G., Accurate transcription initiation by RNA polymerase II in a soluble extract from isolated mammalian nuclei, Nucleic Acids Res. 11 (1983) $1475-1489$. 
[13] Karolchik D., Hinrichs A.S., Furey T.S., Roskin K.M., Sugnet C.W., Haussler D., Kent W.J., The UCSC Table Browser data retrieval tool, Nucleic Acids Res. 32 (2004) D493496.

[14] Huin C., Corriveau L., Bianchi A., Keller J.M., Collet P., Kremarik-Bouillaud P., Domenjoud L., Bécuwe P., Schohn H., Ménard D., Dauça M., Differential expression of peroxisome proliferator-activated receptors (PPARs) in the developing human fetal digestive tract, J. Histochem. Cytochem. 48 (2000) 603-611.

[15] Stein G.H., T98G: an anchorage-independent human tumor cell line that exhibits stationary phase G1 arrest in vitro, J. Cell. Physiol. 99 (1979) 43-54.

[16] Biedler J.L., Roffler-Tarlov S., Schachner M., Freedman L.S., Multiple neurotransmitter synthesis by human neuroblastoma cell lines and clones, Cancer Res. 38 (1978) 3751-3757.

[17] Fogh J., Trempe G., New human tumor cell lines, in: Fogh J (Ed.), Human Tumor Cells In Vitro. New York: Plenum Press; 1975, pp.115-141.

[18] Brattain M.G., Fine W.D., Khaled F.M., Thompson J., Brattain D.E., Heterogeneity of malignant cells from a human colonic carcinoma, Cancer Res. 41 (1981) 1751-1756.

[19] Brooks S.C., Locke E.R., Soule H.D., Estrogen receptor in a human cell line (MCF-7) from breast carcinoma, J. Biol. Chem. 248 (1973) 6251-6253.

[20] Kaighn M.E., Narayan K.S., Ohnuki Y., Lechner J.F., Jones L.W., Establishment and characterization of a human prostatic carcinoma cell line (PC-3), Invest. Urol. 17 (1979) 1623.

[21] Chomczynski P., Sacchi N., Single-step method of RNA isolation by acid guanidium thiocyanate-phenol-chloroform extraction, Anal. Biochem. 162 (1987) 156-159.

[22] Murad H., Collet P., Huin-Schohn C., Al-Makdissy N., Kerjan G., Chedotal A., Donner M., Devignes M.D., Bécuwe P., Schohn H., Domenjoud L., Dauça M., Effects of PPAR and 
RXR ligands in semaphorin 6B gene expression of human MCF-7 breast cancer cells, Int. J. Oncol. 28 (2006) 977-984.

[23] Hanauer A., Mandel J.L., The glyceraldehyde 3 phosphate dehydrogenase gene family: structure of a human cDNA and of an $\mathrm{X}$ chromosome linked pseudogene; amazing complexity of the gene family in mouse, EMBO J. 3 (1984) 2627-2633.

[24] Gobin S., Bonnefont J.P., Prip-Buus C., Mugnier C., Ferrer M., Demaugre F., Saudubray J.M., Rostane H., Djouadi F., Wilcox W., Cederbaum S., Haas R., Nyhan W.L., Green A., Gray G., Girard J., Thuillier L., Organization of the human liver carnitine palmitoyltransferase 1 gene (CPT1A) and identification of novel mutations in hypoketotic hypoglycaemia, Human Genet. 111 (2002) 179-189.

[25] Louet J.F., Le May C., Pegorier J.P., Decaux J.F., Girard J., Regulation of liver carnitine palmitoyltransferase I gene expression by hormones and fatty acids, Biochem. Soc. Trans. 29 (2001) 310-316.

[26] Stolk J.A., Jiang Y., Day C.H., Klee J.I., Zhang X., Dillon D.C., Houghton R.L., Harlan D., Reed S.G., Xu J., P704P, P712P, and P775P: A genomic cluster of prostate-specific genes, The Prostate 60 (2004) 214-226.

[27] Castelein H., Declercq P., Baes M., DNA binding preferences of PPAR alpha/RXR alpha heterodimers, Biochem. Biophys. Res. Commun. 233 (1997) 91-95.

[28] Bardot O., Clemencet M., Passilly P., Latruffe N., The analysis of modified peroxisome proliferator responsive elements of the peroxisomal bifunctional enzyme in transfected HepG2 cells reveals two regulatory motifs, FEBS Lett. 360 (1995) 183-186.

[29] Barrero M.J., Camarero N., Marrero P.F., Haro D., Control of human carnitine palmitoyltransferase II gene transcription by peroxisome proliferator-activated receptor 
through a partially conserved peroxisome proliferator-responsive element, Biochem. J. 369 (2003) 721-729.

[30] Bera T.K., Huynh N., Maeda H., Sathyanarayana B., Lee B., Pastan I., Five POTE paralogs and their splice variants are expressed in human prostate and encode proteins of different lengths, Gene 337 (2004) 45-53.

[31] Mandard S., Müller M., Kersten S., Peroxisome proliferator-activated receptor $\alpha$ target genes, Cell. Mol. Life Sci. 61 (2004) 393-416. 
Table 1

Sequences of primers used in RT/PCR analyses

\begin{tabular}{|c|c|c|}
\hline Genes & Sequences (5'-3') sense & Sequences (5'-3') antisense \\
\hline POTE & CAATGCCAGGAAGATGAATGTGCG & TCTCTGGCCGTCTGTCCAGATAGAT \\
\hline GAPDH & GGTGAAGGTCGGTGTCAACG & GGGATCGCGCTCCTGGAAGG \\
\hline CPT1 $\boldsymbol{\alpha}$ & TGCTTTACAGGCGCAAACTG & TGGAATCGTGGATCCCAAA \\
\hline
\end{tabular}




\section{Table 2}

\section{BLAT Search of DR0/3 motives of RE1029 in human genome}

\begin{tabular}{|c|c|c|c|c|c|c|c|c|c|c|}
\hline QSIZE & SCORE & IDENTITY & CHRO & STRAND & Position & SPAN & Gene & $\begin{array}{c}\text { Distance } \\
\text { from the } \\
\text { Gene }\end{array}$ & Accession & Group \\
\hline 21 & $/$ & $/$ & 10 & $/$ & $/$ & $/$ & ANKRD30A & $/$ & NM_052997 & $/$ \\
\hline 21 & $/$ & $/$ & 10 & $/$ & $/$ & $/$ & ANKRD26 & NM_014915 & $/$ \\
\hline 21 & $/$ & $/$ & 8 & $/$ & $/$ & $/$ & POTE8 & $/$ & AY462869 & 1 \\
\hline
\end{tabular}

\begin{tabular}{|c|c|c|c|c|c|c|c|c|c|c|}
\hline 21 & 21 & $100.0 \%$ & 15 & - & $19293710-19293730$ & 21 & POTE15 & \#10kb & NM 207355 \\
\hline 21 & 21 & $100.0 \%$ & & - & $19294994-19295014$ & 21 & POTE15 & \#10kb & NM 207355 \\
\hline 21 & 21 & $100.0 \%$ & 18 & - & $14490820-14490840$ & 21 & BX649118 (POTE18) & \#5kb & BX649118 \\
\hline 21 & 19 & $95.3 \%$ & & - & $14492101-14492121$ & 21 & BX649118 (POTE18) & \#5kb & BX649118 \\
\hline 21 & 21 & $100.0 \%$ & 21 & + & $13945397-13945417$ & 21 & ANKRD21 (POTE21) & \#10kb & NM 174981 \\
\hline 21 & 19 & $95.3 \%$ & & + & $13946037-13946057$ & 21 & ANKRD21 (POTE21) & \#10kb & NM_174981 \\
\hline
\end{tabular}

\begin{tabular}{|c|c|c|c|c|c|c|c|c|c|}
\hline 21 & 21 & $100.0 \%$ & \multirow{7}{*}{14} & - & $18664711-18664731$ & 21 & POTE1 $4 \alpha$ & $\# 10 \mathrm{~kb}$ & NM_001005356 \\
\hline 21 & 21 & $100.0 \%$ & & - & $18667648-18667668$ & 21 & POTE1 $4 \alpha$ & $\# 10 \mathrm{~kb}$ & NM_001005356 \\
\hline 21 & 21 & $100.0 \%$ & & - & $18671398-18671418$ & 21 & POTE1 $4 \alpha$ & $\# 10 \mathrm{~kb}$ & NM_001005356 \\
\hline 21 & 21 & $100.0 \%$ & & - & $19042356-19042376$ & 21 & POTE1 $4 \beta$ & $\# 10 \mathrm{~kb}$ & NM_207513 \\
\hline 21 & 21 & $100.0 \%$ & & + & $18673035-18673055$ & 21 & POTE1 $4 \alpha$ & $\# 10 \mathrm{~kb}$ & NM_001005356 \\
\hline 21 & 21 & $100.0 \%$ & & + & $19043994-19044014$ & 21 & POTE1 $4 \beta$ & $\# 10 \mathrm{~kb}$ & NM_207513 \\
\hline 21 & 21 & $100.0 \%$ & & + & $19048908-19048928$ & 21 & POTE1 $4 \beta$ & $\# 10 \mathrm{~kb}$ & NM_207513 \\
\hline 21 & 21 & $100.0 \%$ & \multirow{3}{*}{22} & $=$ & $14620001-14620021$ & 21 & ACTBL1 (POTE22) & $\# 10 \mathrm{~kb}$ & NM 144590 \\
\hline 21 & 21 & $100.0 \%$ & & + & $14621639-14621659$ & 21 & ACTBL1 (POTE22) & $\# 10 \mathrm{~kb}$ & NM 144590 \\
\hline 21 & 21 & $100.0 \%$ & & + & $14626553-14626573$ & 21 & ACTBL1 (POTE22) & $\# 10 \mathrm{~kb}$ & NM 144590 \\
\hline 21 & 21 & $100.0 \%$ & & - & $131748437-131748457$ & 21 & POTE $2 \gamma$ & $\# 10 \mathrm{~kb}$ & NM_001004054 \\
\hline 21 & 21 & $100.0 \%$ & & + & $130536994-130537014$ & 21 & POTE $2 \alpha$ & $\# 10 \mathrm{~kb}$ & AY 462868 \\
\hline 21 & 21 & $100.0 \%$ & 2 & + & $130538981-130539001$ & 21 & POTE $2 \alpha$ & $\# 10 \mathrm{~kb}$ & AY462868 \\
\hline 21 & 19 & $95.3 \%$ & & + & $130534651-130534671$ & 21 & POTE $2 \alpha$ & $\# 10 \mathrm{~kb}$ & AY462868 \\
\hline
\end{tabular}

The size of the DRO/3 motif in RE1029 is 21 nucleotides; Score, number of homologous nucleotides; CHRO, chromosome. The groups of POTE genes are defined in reference [5] 
Table 3

Microarray data from T98-G cells treated with Wy-14,643 for 24 hours

\begin{tabular}{|cccc|}
\hline $\begin{array}{c}\text { Accession } \\
\text { Number }\end{array}$ & $\begin{array}{c}\text { Fold } \\
\text { Change }\end{array}$ & $\begin{array}{c}\text { Gene } \\
\text { Description }\end{array}$ & $\begin{array}{c}\text { Chromosome } \\
\text { Mapping }\end{array}$ \\
\hline NM_207355 & -1.4 & POTE-15 & 15 \\
BX649118 & -1.9 & POTE-18 & 18 \\
NM_174981 & -1.2 & POTE-21 & 21 \\
NM_014915 & -1.2 & ANKRD26 & 10 \\
NM_052997 & -1.6 & ANKRR30A & 10 \\
\hline
\end{tabular}

FIGURE LEGENDS 


\section{Fig.1. Immunoselection and PCR amplification}

The immunoselection/PCR protocol used to isolate human genomic fragments containing binding sites for PPARs is represented. Clones harboring ISFs were spotted onto nylon membranes and tested for their capacity to bind PPARs in Southwestern blotting using in vitro translated, radiolabeled PPARs. A clone harboring the rat acyl CoA oxidase gene promoter sequence, which contains a canonical DR1, was used as a positive control (+). The negative control (-) was a clone with an empty plasmid. A signal was obtained with ISF1029. Its full-length sequence is presented in the inset and the DR0/3 motif (RE1029) is indicated.

\section{Fig.2. Gel mobility shift and supershift assays}

HepG2 nuclear proteins $(12.5 \mu \mathrm{g})$ were incubated in the binding buffer with $1 \mu \mathrm{g}$ of dIdC before adding the labeled RE1029 probe (lane 1). Evidence for the presence of PPARs and particularly of PPAR $\alpha$ subtype (lane 3) in the DNA-proteins complexes was obtained with panPPAR antibodies (lane 2) and anti-PPAR $\alpha$ antibodies (lane 3), used at a dilution of 1/40.

\section{Fig.3. POTE genes expression in various human cell lines}

Total RNA was extracted from cells and submitted to semiquantitative RT-PCR using specific primers for POTE and GAPDH genes. The expected sizes of the PCR products for POTE and GAPDH are $386 \mathrm{bp}$ and $231 \mathrm{bp}$, respectively.

\section{Fig. 4. Effect of PPAR and RXR agonists on POTE genes expression}

Caco-2 cells were treated for $24 \mathrm{~h}$ with $500 \mu \mathrm{M}$ fenofibrate alone or with $1 \mu \mathrm{M}$ 9-cis retinoic acid. RT-PCR analyses were carried out for POTE and GAPDH. The ratios between the intensities of the POTE and GAPDH signals were determined. The bar graphs represent the mean \pm SD of 3 independent experiments. ${ }^{*}, P<0.05 ;{ }^{* *}, P<0.01$ versus control; 9-cis-RA, 9-cisretinoic acid; FF, fenofibrate. 